\title{
Diagnosis and management of acute ischemic stroke: speed is critical
}

\author{
Tapuwa D. Musuka MBChB, Stephen B. Wilton MD, Mouhieddin Traboulsi MD, Michael D. Hill MD
}

CMAJ Podcasts: author interview at soundcloud.com/cmajpodcasts/hill-stroke

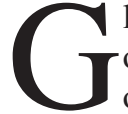
lobally, stroke is the second leading cause of death. ${ }^{1}$ The estimated 62000 strokes that occur each year in Canada affect all age groups, from neonates to elderly people, with occurrence rates rising by age. The lifetime risk of overt stroke is estimated at one in four by age 80 years, and the lifetime risk of silent or covert stroke is likely closer to $100 \%$. Stroke affects men and women equally and causes major social and economic burdens to society, with direct costs above $\$ 3$ billion annually in Canada. ${ }^{2}$ Acute stroke and acute coronary syndromes have many similarities. Here, we review the diagnosis and management of acute ischemic stroke and compare its treatment with that of acute coronary syndrome, to help illustrate how the rapid relief of arterial occlusion and restoration of normal blood flow can save lives and prevent disability. This narrative review is based upon a critical appraisal of relevant clinical trials (Box 1).

Stroke is a syndrome. Broadly, there are two types of stroke, either ischemic (in $85 \%$ of cases) or hemorrhagic (in 15\%). Hemorrhagic strokes are divided equally into intracerebral hemorrhage and atraumatic subarachnoid hemorrhage. The older terms "cerebrovascular accident" and "reversible ischemic neurologic deficit" are not meaningful and should no longer be used. The severity of ischemic stroke ranges from clinically mild or transient (termed a minor stroke or transient ischemic attack) to very severe (termed major ischemic stroke), but the underlying causes are identical. The distinction between transient ischemic attack and ischemic stroke is no more than one of severity; therefore, it is not useful to think of these two entities in separate categories.

\section{Box 1: Evidence used in this review}

We searched PubMed from 1955 to 2015 for articles about stroke and acute coronary syndrome. We reviewed the bibliographies of identified articles for additional pertinent studies. A group of stroke physicians and interventional cardiologists (including but not limited to the author team) provided expert review of the literature.

\section{How do the causes of ischemic stroke and coronary syndromes compare?}

Ischemic stroke syndromes have a multitude of possible causes, characterized by a rule of quarters: $25 \%$ cardioembolic, $25 \%$ arteroembolic (largeartery disease), 25\% lacunar (small-vessel disease) and $25 \%$ due to other causes, with global variation in proportions by population. ${ }^{3}$ In contrast, acute coronary syndromes are overwhelmingly due to rupture or erosion of an atherosclerotic plaque, with in situ formation of thrombus on the plaque, which in turn causes arterial obstruction. ${ }^{4}$ We compare stroke syndromes and coronary syndromes in Table 1.

Arterial occlusion in ischemic stroke is most commonly embolic: either cardioembolic, from causes such as atrial fibrillation or valvular heart disease, or arteroembolic, from atherosclerotic disease in the extracranial cervical carotid or vertebral artery. Plaque rupture in the extracranial cervical arteries with thrombus formation is thought to be mechanistically identical with the same process in the coronary arteries, but most commonly results in distal embolization of thrombus to the brain (arteroembolism), rather than in situ vessel occlusion. There is increasing recognition that acute coronary syndromes may involve arteroembolic mechanisms of occlusion of distal coronary arteries, exactly analogous to ischemic stroke caused by arteroembolism from the extracranial carotid artery. ${ }^{5,6}$ A less common cause of intracranial artery occlusion is rupture of an intra-
Competing interests: See end of article.

Correspondence to: Michael D. Hill, michael.hill@ucalgary.ca

CMAJ 2015. DOI:10.1503 /cmaj.140355

\section{KEY POINTS}

- Ischemic stroke and acute coronary syndromes are similar because they are both caused by sudden arterial occlusion.

- Different causes and pathological processes can result in occlusion; therefore, approaches to treatment differ as well.

- Time to treatment is a critical factor affecting outcome for both ischemic stroke and acute coronary syndromes.

- As is the case for acute coronary syndromes, coordinated systems of care are required to achieve good outcomes in patients with acute ischemic stroke. 
cranial atherosclerotic plaque with in situ thrombus formation, exactly analogous to the situation in the coronary circulation.

Intrinsic small-vessel disease is inferred in a quarter of ischemic strokes, but a good understanding of the mechanism is lacking because these arteries are too small to be reliably imaged in vivo during an acute stroke event. In studies of small-vessel strokes, pathologic examination has suggested that microatheroma with plaque rupture was the most common cause of occlusion, followed by microembolism. ${ }^{7,8}$

Stroke registries in which the mechanism has been prospectively identified show that for as many as one-quarter of patients, no clear cause of the stroke is identified. Many of these strokes have imaging characteristics supporting an embolic mechanism; hence, they are labelled as embolic stroke of undetermined source (widely known as ESUS). ${ }^{9}$ Less common causes of both ischemic stroke and acute coronary syndromes include arterial dissection, vasospasm, vasculitis and hypercoagulable states.

\section{What are the signs and symptoms of acute ischemic stroke?}

Stroke syndromes present clinically as neurologic deficits of sudden onset. Symptoms depend upon the affected region of brain, which in turn is de- fined by the arterial anatomy involved. Although some features are more or less typical of hemorrhagic forms of stroke, as distinct from ischemic stroke, none are sufficiently discriminatory to allow clinical diagnosis of stroke type. Therefore, brain and neurovascular imaging in the acute phase is required for all strokes. Common symptoms of stroke in the left hemisphere include aphasia, right hemiparesis and right hemianopia, and in the right hemisphere, left hemispatial neglect, left hemiparesis and left hemianopia. The majority (90\%) of strokes are supratentorial; as such, the public can be taught to recognize and act upon stroke using the acronym FAST, for facial droop, arm drop, speech disturbance and time. Posterior circulation or infratentorial stroke has a multitude of additional symptoms, including diplopia, bulbar palsies, dysphagia, unilateral dysmetria and incoordination, as well as reduced levels of consciousness. Although headache or head, facial or neck pain may be an ancillary symptom, stroke is typically painless. The most important historical feature of stroke is the suddenness of its onset.

Identification of a stroke syndrome is relatively easy: sudden onset of acute neurologic symptoms, peaking within a few minutes, is deemed a stroke until proven otherwise. However, detailed diagnosis and management are highly dependent upon clinical assessment of the history and physical examination, because symp-

\begin{tabular}{|c|c|c|}
\hline Characteristic & Acute ischemic stroke syndromes & Acute coronary syndromes \\
\hline Pathophysiology & $\begin{array}{l}\text { Heterogeneous: cardioembolic, artery-to- } \\
\text { artery embolization, small-vessel disease, } \\
\text { cryptogenic or embolic stroke of } \\
\text { undetermined source (also known as ESUS) }\end{array}$ & $\begin{array}{l}\text { Homogeneous: rupture of plaque and } \\
\text { in situ formation of occlusive thrombus } \\
\text { (most cases) }\end{array}$ \\
\hline Diagnosis & $\begin{array}{l}\text { Clinical; imaging is mandatory and used for } \\
\text { treatment decisions }\end{array}$ & $\begin{array}{l}\text { Clinical assessment, electrocardiography } \\
\text { and imaging used for risk stratification } \\
\text { and prognostication }\end{array}$ \\
\hline Thrombolytics & $\begin{array}{l}\text { Alteplase (tPA) is standard; other } \\
\text { thrombolytic agents still under } \\
\text { investigation }\end{array}$ & $\begin{array}{l}\text { Tenecteplase is standard; alteplase (tPA), } \\
\text { reteplase and streptokinase are } \\
\text { alternative proven therapies }\end{array}$ \\
\hline Endovascular therapy & $\begin{array}{l}\text { Endovascular thrombectomy proven for } \\
\text { patients selected by imaging and with fast } \\
\text { treatment paradigms }\end{array}$ & $\begin{array}{l}\text { Primary percutaneous coronary } \\
\text { intervention established for STEMI, } \\
\text { within } 12 \mathrm{~h} \text { of symptom onset }\end{array}$ \\
\hline $\begin{array}{l}\text { Organized care units } \\
\text { or wards }\end{array}$ & $\begin{array}{l}\text { Associated with proven improvement in } \\
\text { mortality and morbidity, but not yet widely } \\
\text { established throughout Canada }\end{array}$ & $\begin{array}{l}\text { Shown to improve mortality and } \\
\text { morbidity; well established worldwide }\end{array}$ \\
\hline Milder clinical syndromes & $\begin{array}{l}\text { TIA and minor stroke require same-day } \\
\text { assessment, diagnosis and management to } \\
\text { prevent major acute stroke }\end{array}$ & $\begin{array}{l}\text { Unstable angina and NSTEMI } \\
\text { require urgent assessment, diagnosis, risk } \\
\text { stratification and often invasive } \\
\text { management to prevent major } \\
\text { cardiovascular events }\end{array}$ \\
\hline
\end{tabular}


toms and signs vary tremendously according to the region of the brain that is affected (Box 2).

\section{How is the diagnosis confirmed?}

Brain and neurovascular imaging is required for diagnosis. The current standard is noncontrast computed tomography (CT) of the head because it is fast and widely available. When interpreted by an expert, head CT can rule in a diagnosis of hemorrhagic stroke (intracerebral or subarachnoid hemorrhage) with over $95 \%$ accuracy. Head $\mathrm{CT}$ can also rule in a diagnosis of major stroke in about two-thirds of cases in which ischemic changes are evident, but it is highly insensitive to the diagnosis of minor stroke. ${ }^{10-12}$ Small-volume ischemic change is simply beyond the resolution of CT; therefore, a "normal" scan in the scenario of minor stroke neither confirms nor excludes ischemia. Magnetic resonance imaging (MRI) has greater spatial resolution to detect brain ischemia in transient ischemic attack or minor ischemic stroke and is the modality of choice to make an inclusive imaging diagnosis of minor stroke in cases where the deficits are very mild. ${ }^{12}$

For all presentations of acute stroke syndrome, we recommend CT angiography immediately following noncontrast head CT. ${ }^{13,14}$ Identification of the occluded intracranial vessel and evaluation of the extracranial carotid, extracranial vertebral, aortic arch and proximal great vessels is required for management of both transient ischemic attack or minor stroke and major ischemic stroke, if not immediately then over the next several days. ${ }^{15}$ In cases of hemorrhagic stroke, intracranial CT angiography will identify intracranial aneurysm as the cause of subarachnoid hemorrhage or show the source of bleeding in intracerebral hemorrhage as a "spot" sign. ${ }^{16}$ Although MRI has greater sensitivity for the small-volume ischemia observed in transient ischemic attack or minor stroke, it is used only in situations where there is no time pressure to offer treatment, typically as follow-up imaging. Unlike the situation for acute coronary syndromes, where serum troponin and electrocardiography (ECG) are helpful diagnostic biomarkers, similar blood or simple electrophysiologic tests are not available in stroke. Imaging is the biomarker. See Box 3.

\section{How should the patient with acute ischemic stroke be treated?}

When given within 4.5 hours after onset of ischemic stroke, intravenous administration of recombinant tissue plasminogen activator (alteplase) has been shown in randomized controlled trials to de- crease functional disability, with an absolute risk reduction of $7 \%-13 \%$ relative to placebo; it has thus become the leading specific treatment recommended for acute management of ischemic stroke. ${ }^{18-21}$ Treatment efficacy wanes rapidly, and risk of harm increases with time elapsed from symptom onset; hence the urgent need for timely diagnosis and treatment. ${ }^{22}$

Endovascular treatment is now a proven therapy for major acute ischemic stroke. A Canadianled multinational trial, the Endovascular treatment for Small Core and Anterior circulation Proximal occlusion with Emphasis on minimizing CT to recanalization times (ESCAPE) trial, has convincingly shown that endovascular thrombectomy using contemporary devices substantially reduces both morbidity and mortality. ${ }^{23}$ The ESCAPE findings have confirmed results from the Netherlands $^{24}$ and a phase IIb study from Australia. ${ }^{25}$ Two smaller studies, one from the United States and the other from Spain, have provided further confirmatory findings. ${ }^{26,27}$ These results

\section{Box 2: Diagnosis and assessment of acute stroke syndrome}

- Check $A B C s$ (airway, breathing and circulation) first. In some patients with stroke, the level of consciousness is reduced, and intubation may be required. Rarely, there is circulatory instability due to arrhythmia or other concurrent cardiac disease.

- Perform a quick assessment of degree of disability:

- Speech and spatial perception: Aphasia or hemispatial neglect?

- Vision: Hemianopia or quadrantanopia?

- Hemiparesis: Facial droop? Antigravity arm strength? Antigravity leg strength?

- Hemianesthesia: Check gross light touch on face, arm and leg.

- Coordination and walking: If possible, have the patient get out of bed and try to walk.

- Use the National Institutes of Health Stroke Scale (NIHSS) to guide assessment of disability:

- NIHSS $=0-5$ : transient ischemic attack (NIHSS $=0$ and no signs on examination) or minor stroke (NIHSS 1-5)

- NIHSS = 6-10: moderate disabling stroke

- $\mathrm{NIHSS}=11-20:$ moderate to severe disabling stroke

- $\mathrm{NIHSS} \geq 20$ : severe, life-threatening stroke

\section{Box 3. How diagnostics defined treatment in stroke and coronary} syndromes

The evolution of thrombolytic therapy for ST-segment elevation myocardial infarction was facilitated by the wide availability and ease of use of electrocardiography. ST-segment elevation was easily recognized and provided a good method of identifying patients who would benefit from treatment. In contrast, the development of thrombolysis for stroke was dependent upon imaging to confirm the type of stroke. As CT imaging became more widely available in the 1990 s, it became possible to rapidly rule out hemorrhagic stroke and to test thrombolysis for ischemic stroke in clinical trials. Thus, the development of thrombolysis for stroke, although first considered and attempted in $1958,{ }^{17}$ was delayed by the necessary development of noninvasive imaging. 
apply only under the following conditions: patients have been selected on the basis of CT and CT angiography, time from imaging to reperfusion of the blocked artery is less than 90 minutes, contemporary devices are available for use by experts to open the blocked artery, and support from a dedicated stroke unit is available for inpatient stroke care. Thus, while the technology is enabling, this procedure will be available only in tertiary hospitals that have stroke teams with the expertise to use timely imaging and intervention and the ability to provide follow-up hyperacute care on a stroke unit.

Only patients with disabling acute ischemic strokes are considered eligible for thrombolysis. The definition of "disabling" varies by stage of life and occupation. For example, a cortical hand syndrome (score of 0 on National Institutes of Health Stroke Scale) may be disabling for a professional musician but not for an elderly retiree. A patient with a higher score on this scale is more likely to be considered disabled. Stroke is sometimes associated with a major underlying life-limiting illness (e.g., pancreatic carcinoma causing hypercoagulable state or stroke associated with advanced dementia); in such cases acute treatment is not indicated, as death is an inevitable outcome. Deciding who should be treated requires experience, judgment and appreciation of the entire clinical context. Broader use of advance directives would help with this kind of decision-making.

At least half of patients with major ischemic stroke arrive more than 4.5 hours after stroke onset and are therefore not eligible for thrombolysis. ${ }^{28}$ This delay in presentation may result from a failure to recognize stroke, principally by the family or friends. Alternatively, stroke commonly renders the patient unable to initiate his or her own call for help, so if the patient is alone when the stroke occurs, there will be a delay until the person is found by family or friends. Registries have shown that in half of the cases, delay is caused by hesitation to contact medical services after symptom onset. ${ }^{29,30}$ All patients with stroke should ideally be treated on a geographically discrete stroke unit by a multidisciplinary team, as described in further detail below.

Half or more of all ischemic strokes are classified as transient ischemic attack or minor stroke, and most of these patients are not offered thrombolysis because their symptoms are not judged to be disabling. These cases must be managed aggressively to prevent progression to major stroke and to prevent early recurrent major stroke. This means same-day diagnostic work-up to establish whether carotid artery atherosclerotic disease or atrial fibrillation are implicated, which would necessitate cause-specific therapy with carotid revascularization or anticoagulation, respectively..$^{14,31}$

\section{Time is brain!}

\section{Minutes count}

Speed of treatment is a critical factor in determining the outcome of thrombolytic and/or endo-

\section{Box 4: Acute revascularization for ST-segment elevation myocardial infarction ${ }^{32}$}

Patients with ST-segment elevation myocardial infarction (STEMI) most likely have a large, acute occlusion of the coronary artery that will be amenable to emergent revascularization with thrombolysis or primary percutaneous coronary intervention (PCI). These patients represent about $40 \%$ of all cases of acute coronary syndrome. ${ }^{4,33}$ Initial thrombolysis trials dating back to the 1970 s had neutral or negative results. In 1986, with the publication of the landmark GISSI Trial (Gruppo Italiano per la Sperimentazione della Streptochinasi nell'Infarto Miocardico), thrombolysis entered the mainstream. ${ }^{34}$ The GISSI trial showed that the sooner streptokinase was administered, the better were the chances of recovery, with significant improvement in mortality rates. Numerous other clinical trials followed, reinforcing the evidence for rapid administration of streptokinase. Eventually, streptokinase was supplanted by newer agents, such as recombinant tissue plasminogen activator (alteplase) and tenecteplase, which have superior efficacy, with a treatment window of six hours from symptom onset. These trials also resulted in the concept of door-to-needle time as a measure of system performance.

The limitations of systemic thrombolysis for STEMI, including significant decrease in efficacy with prolonged ischemic time, failure of reperfusion, risk of reinfarction and an approximately $1 \%$ risk of intracranial hemorrhage, prompted development of local therapies: first endovascular thrombolysis and then PCl. ${ }^{35}$ Primary PCl is now the preferred strategy, but only where coordinated systems are available to ensure timely access. For patients with STEMI, immediate transfer to a $\mathrm{PCl}$-capable institution is recommended, provided this transfer can be achieved within 90 minutes and provided that total ischemic time is less than 12 hours. If this is not feasible, and particularly for patients who present within two to three hours of symptom onset, thrombolytic therapy should be given before arrival at the hospital or at the non-PCl-capable hospital, followed by transfer to a PCl-capable centre.

Coronary care units are the cornerstone of post-myocardial infarction (MI) care. The development of this type of unit began in the 1960s, the first in Toronto being established in 1965. By the 1980s, when the evidence for thrombolysis for acute MI became accepted, infrastructure was already in place for treatment of acute MI, which made the goal of short door-to-needle times highly feasible. Furthermore, admission to a coronary care unit is beneficial because this setting offers rapid identification and treatment of malignant arrhythmias, diagnostic expertise and early introduction of medical treatments. ${ }^{6,36}$ 
vascular treatment for patients with disabling acute ischemic stroke. In this regard, it may be useful to consider how the treatment of myocardial infarction (MI) has evolved (see Box 4). ${ }^{4,6,32-36}$ Rapid diagnosis of acute $\mathrm{MI}$ is facilitated principally by ECG. Measurement of serum enzymes (creatine kinase MB fraction and troponin T/I) is not useful in the first hour. The clinical history, physical examination and ECG findings are the diagnostic mainstays. In some large cities, paramedic personnel perform ECG and can transmit the tracing electronically to the attending cardiologist, which allows treatment decisions to be made en route. In some jurisdictions, ambulance-based thrombolysis is initiated on this basis alone. ${ }^{37,38}$ Electronic transmission of the ECG tracing has also facilitated a direct-to-catheterization-laboratory approach for primary percutaneous coronary intervention, with bypass of the emergency department and reduction in door-to-balloon time, which has led to better outcomes for patients with MI. It remains true that when delays to primary percutaneous coronary intervention are expected (e.g., because of transport distance), it is better to treat rapidly with intravenous thrombolysis. ${ }^{37}$

In cases of suspected ischemic stroke, bypassing the emergency department is difficult because of the need for imaging. The particular stroke type (ischemic v. hemorrhagic) may be suspected before arrival at the hospital, but cannot be confirmed without imaging. Rapid in-hospital processes and a team approach are required to reduce door-to-needle times. A median time of $20 \mathrm{~min}$ utes was shown to be possible in a cohort study from Helsinki, ${ }^{39}$ but in North America median times of 60 minutes or more are typical. ${ }^{30}$ On average, for every minute of delay after middle cerebral artery occlusion, 1.9 million neurons, 14 billion synapses and $12 \mathrm{~km}$ of myelinated fibres are destroyed. ${ }^{40}$ Efforts to reduce door-to-treatment times for stroke are continuing. Research studies are underway in Berlin and Houston to examine the effects of placing CT scanners in ambulances to allow rapid imaging, remote transmission of imaging data for expert review and a thrombolysis deci- sion, so that paramedics can deliver thrombolytic therapy in the ambulance. ${ }^{41}$ Ambulance-based CT may eventually facilitate a direct-to-angiographysuite approach for acute ischemic stroke, similar to what is already in place for MI.

\section{Hours count}

Distinguishing clinically between transient ischemic attack and minor stroke is not particularly helpful for prognosis because both are associated with substantial early and 90-day risks of major ischemic stroke, and urgent investigation and management are therefore warranted for both. ${ }^{15,42,43}$ Cohort studies have shown that up to one-third of inpatients with a clinical diagnosis of transient ischemic attack (no residual deficits on examination) have evidence of ischemia on MRI. ${ }^{11,44}$ Almost all patients with minor stroke have small infarcts that can be visualized by MRI. ${ }^{45}$ In this way, transient ischemic attack and minor stroke are conceptually similar to non-ST-segment elevation MI (Box 5). ${ }^{46}$

The risk of disabling stroke after transient ischemic attack or minor stroke is substantial and is heavily "front-end loaded." ${ }^{47}$ Recognition and early (i.e., same-day) evaluation and treatment may substantively reduce this risk. ${ }^{48-50}$ Dual antiplatelet regimens for the short-term are warranted and continue to be investigated. ${ }^{51,52}$ Carotid artery revascularization and anticoagulation for atrial fibrillation are proven effective treatments that prevent stroke. ${ }^{53,54}$ For patients without these conditions, transient ischemic attack presents a golden opportunity to prevent future stroke by intervening on lifestyle and vascular risk factors. ${ }^{31}$

\section{What care should be provided in hospital?}

Specialized coronary care units are prevalent worldwide, but the same is not true for stroke units. ${ }^{55}$ However, organized stroke unit care care provided by multidisciplinary teams that exclusively manage patients with stroke in a dedi-

\section{Box 5: Non-ST-segment elevation acute coronary syndromes ${ }^{46}$}

Non-ST-segment elevation acute coronary syndromes include unstable angina and non-ST-segment elevation myocardial infarction. Unstable angina is considered an acute coronary syndrome in which there is no detectable release of enzymes (biomarkers of myocardial necrosis). Most patients with acute coronary syndrome have recurrent transient reduction in coronary blood supply caused by formation of thrombus at the site of atherosclerotic plaque rupture and/or vasoconstriction. These events occur as a consequence of platelet aggregation and complex interactions among the vascular wall, leukocytes, platelets and atherogenic lipoproteins. Non-ST-segment elevation myocardial infarction has the same pathophysiology as unstable angina but is distinguished by the release of cardiac markers of myocardial necrosis (e.g., troponin T). Management involves early risk stratification and rapid institution of medical treatments: antiplatelet agents, antithrombotic agents, $\beta$-blockers and statin therapy. Thrombolytic therapy is not indicated for these patients. Early coronary angiography and revascularization are beneficial in high-risk patients with acute coronary syndrome. 
cated ward - should be the standard of care. Randomized controlled trials have shown conclusively that patients treated in dedicated stroke units fare better than those treated in general wards without the same ready access to personnel trained and experienced in managing stroke. ${ }^{56-59}$ The spectrum of stroke syndrome in these studies included both ischemic and hemorrhagic stroke, ranging from mild (transient ischemic attack and minor stroke) to more severe. ${ }^{58}$ In one trial, providing treatment in a stroke unit significantly reduced in-hospital mortality (odds ratio [OR] $0.50,95 \%$ confidence interval [CI] 0.34-0.74), case-fatality rate (OR $0.45,95 \%$ CI $0.28-0.71)$, six-month mortality (OR $0.57,95 \%$ CI 0.39 0.82 ), one-year mortality (OR $0.59,95 \%$ CI 0.42 0.84 ) and rate of discharge to a nursing home (OR $0.61,95 \%$ CI 0.38-0.98). ${ }^{60}$

Patients with stroke who receive organized inpatient care in a stroke unit are more likely to be alive, independent and living at home one year after the stroke. ${ }^{57,60,61}$ These benefits were most apparent in units based in a discrete ward, and there is substantial evidence of avoidance of direct costs when such care is implemented.

\section{Conclusion}

Conceptually, there are broad similarities in the presentation, pathophysiology and treatment of acute ischemic stroke syndromes (from the mildest transient ischemic attack or minor stroke through major ischemic stroke) and acute coronary syndromes. Two unifying concepts are that treatments must be fast and decisive and that organization of care is critical to good outcomes. Acute stroke care is rapidly catching up with acute coronary care. Successful treatment programs for both conditions are highly dependent upon specialized treatment units, provision of care by teams of health care providers and the "chain of survival" from symptom onset to reperfusion.

\section{References}

1. Go AS, Mozaffarian D, Roger VL, et al.; American Heart Association Statistics Committee and Stroke Statistics Subcommittee. Heart disease and stroke statistics - 2014 update: a report from the American Heart Association. Circulation 2014;129:e28-e292.

2. Tracking heart disease and stroke in Canada. Ottawa: Public Health Agency of Canada; 2009. Available: www.phac-aspc. gc.ca/publicat/2009/cvd-avc/pdf/cvd-avs-2009-eng.pdf (accessed 2015 July 21).

3. Ay H, Furie KL, Singhal A, et al. An evidence-based causative classification system for acute ischemic stroke. Ann Neurol 2005;58:688-97.

4. DeWood MA, Spores J, Notske R, et al. Prevalence of total coronary occlusion during the early hours of transmural myocardial infarction. N Engl J Med 1980;303:897-902.

5. Farb A, Burke AP, Tang AL, et al. Coronary plaque erosion without rupture into a lipid core. A frequent cause of coronary thrombosis in sudden coronary death. Circulation 1996;93:1354-63.

6. Falk E. Unstable angina with fatal outcome: dynamic coronary thrombosis leading to infarction and/or sudden death. Autopsy evidence of recurrent mural thrombosis with peripheral embolization culminating in total vascular occlusion. Circulation 1985;71:699-708.

7. Fisher CM. The arterial lesions underlying lacunes. Acta Neuropathol 1968;12:1-15.

8. Fisher CM. Lacunar strokes and infarcts: a review. Neurology 1982:32:871-6.

9. Hart RG, Diener HC, Coutts SB, et al. Embolic strokes of undetermined source: the case for a new clinical construct. Lancet Neurol 2014;13:429-38.

10. Barber PA, Hill MD, Eliasziw M, et al. Imaging of the brain in acute ischaemic stroke: comparison of computed tomography and magnetic resonance diffusion-weighted imaging. J Neurol Neurosurg Psychiatry 2005;76:1528-33.

11. Kidwell CS, Alger JR, Di Salle F, et al. Diffusion MRI in patients with transient ischemic attacks. Stroke 1999;30:1174-80.

12. Kidwell CS, Chalela JA, Saver JL, et al. Comparison of MRI and $\mathrm{CT}$ for detection of acute intracerebral hemorrhage. JAMA 2004;292:1823-30.

13. Casaubon LK, Boulanger JM, Blacquiere D, et al.; Heart and Stroke Foundation of Canada Canadian Stroke Best Practices Advisory Committee. Canadian Stroke Best Practice Recommendations: hyperacute stroke care guidelines, Update 2015. Int J Stroke. 2015 Jul 6 [Epub ahead of print].

14. Coutts SB, Wein TH, Lindsay MP, et al. Canadian best practice recommendations: secondary prevention of stroke guidelines, update 2014. Int J Stroke 2015;10:282-91.

15. Coutts SB, Modi J, Patel SK, et al. CT/CT angiography and MRI findings predict recurrent stroke after transient ischemic attack and minor stroke: results of the prospective CATCH study. Stroke 2012;43:1013-7.

16. Demchuk AM, Dowlatshahi D, Rodriguez-Luna D, et al. Prediction of haematoma growth and outcome in patients with intracerebral haemorrhage using the CT-angiography spot sign (PREDICT): a prospective observational study. Lancet Neurol 2012;11:307-14.

17. Sussman BJ, Fitch TS. Thrombolysis with fibrinolysin in cerebral arterial occlusion. J Am Med Assoc 1958;167:1705-9.

18. Hacke W, Kaste M, Fieschi C, et al. Randomised double-blind placebo-controlled trial of thrombolytic therapy with intravenous alteplase in acute ischaemic stroke (ECASS II). Second European-Australasian Acute Stroke Study Investigators. Lancet 1998;352:1245-51.

19. Hacke W, Kaste M, Bluhmki E, et al. Thrombolysis with alteplase 3 to 4.5 hours after acute ischemic stroke. N Engl J Med 2008;359:1317-29.

20. Lees KR, Bluhmki E, von Kummer R, et al. Time to treatment with intravenous alteplase and outcome in stroke: an updated pooled analysis of ECASS, ATLANTIS, NINDS, and EPITHET trials. Lancet 2010;375:1695-703.

21. Tissue plasminogen activator for acute ischemic stroke. The National Institute of Neurological Disorders and Stroke rt-PA Stroke Study Group. N Engl J Med 1995;333:1581-7.

22. Emberson J, Lees KR, Lyden P, et al. Effect of treatment delay, age, and stroke severity on the effects of intravenous thrombolysis with alteplase for acute ischaemic stroke: a metaanalysis of individual patient data from randomised trials. Lancet 2014;384:1929-35.

23. Goyal M, Demchuk AM, Menon BK, et al.; ESCAPE Trial Investigators. Randomized assessment of rapid endovascular treatment of ischemic stroke. N Engl J Med 2015;372:1019-30.

24. Berkhemer OA, Fransen PS, Beumer D, et al. A randomized trial of intraarterial treatment for acute ischemic stroke. $N$ Engl J Med 2015;372:11-20.

25. Campbell BC, Mitchell PJ, Kleinig TJ, et al.; EXTEND-IA Investigators. Endovascular therapy for ischemic stroke with perfusion-imaging selection. N Engl J Med 2015;372:1009-18.

26. Saver JL, Goyal M, Bonafe A, et al.; SWIFT PRIME Investigators. Stent-retriever thrombectomy after intravenous t-PA vs. t-PA alone in stroke. N Engl J Med 2015;372:2285-95.

27. Jovin TG, Chamorro A, Cobo E, et al.; REVASCAT Trial Investigators. Thrombectomy within 8 hours after symptom onset in ischemic stroke. N Engl J Med 2015;372:2296-306.

28. Kleindorfer D, Kissela B, Schneider A, et al.; Neuroscience Institute. Eligibility for recombinant tissue plasminogen activator in acute ischemic stroke: a population-based study. Stroke 2004;35:e27-9.

29. Barber PA, Zhang J, Demchuk AM, et al. Why are stroke patients excluded from TPA therapy? An analysis of patient eligibility. Neurology 2001;56:1015-20.

30. Tong D, Reeves MJ, Hernandez AF, et al. Times from symptom onset to hospital arrival in the Get with the Guidelines Stroke Program 2002 to 2009: temporal trends and implications. Stroke 2012;43:1912-7. 
31. Johnston DC, Hill MD. The patient with transient cerebral ischemia: a golden opportunity for stroke prevention. CMAJ 2004;170:1134-7.

32. O'Gara PT, Kushner FG, Ascheim DD, et al. 2013 ACCF/ AHA guideline for the management of ST-elevation myocardial infarction: a report of the American College of Cardiology Foundation/American Heart Association Task Force on Practice Guidelines [published erratum in: Circulation 2013; 128(25):e481]. Circulation 2013;127:e362-425.

33. Hellermann JP, Reeder GS, Jacobsen SJ, et al. Longitudinal trends in the severity of acute myocardial infarction: a population study in Olmsted County, Minnesota. Am J Epidemiol 2002;156:246-53.

34. Rovelli F, De Vita C, Feruglio GA, et al. GISSI trial: early results and late follow-up. Gruppo Italiano per la Sperimentazione della Streptochinasi nell'Infarto Miocardico. J Am Coll Cardiol 1987;10(Suppl B):33B-9B

35. Topol EJ, Califf RM, George BS, et al. A randomized trial of immediate versus delayed elective angioplasty after intravenous tissue plasminogen activator in acute myocardial infarction. N Engl J Med 1987;317:581-8.

36. Rotstein Z, Mandelzweig L, Lavi B, et al. Does the coronary care unit improve prognosis of patients with acute myocardial infarction? A thrombolytic era study. Eur Heart J 1999;20:813-8.

37. Armstrong PW, Gershlick AH, Goldstein P, et al. Fibrinolysis or primary $\mathrm{PCI}$ in ST-segment elevation myocardial infarction. N Engl J Med 2013;368:1379-87.

38. Firanescu C, Wilbers R, Meeder JG. Safety and feasibility of prehospital thrombolysis in combination with active rescue PCI strategy for acute ST-elevation myocardial infarction. Neth Heart J 2005;13:300-4.

39. Meretoja A, Strbian D, Mustanoja S, et al. Reducing in-hospital delay to 20 minutes in stroke thrombolysis. Neurology 2012;79:306-13.

40. Saver JL. Time is brain - quantified. Stroke 2006;37:263-6.

41. Ebinger M, Rozanski M, Waldschmidt C, et al.; STEMO Consortium. PHANTOM-S: the prehospital acute neurological therapy and optimization of medical care in stroke patients study. Int J Stroke 2012;7:348-53.

42. Johnston SC, Gress DR, Browner WS, et al. Short-term prognosis after emergency department diagnosis of TIA. JAMA 2000;284:2901-6.

43. Merwick A, Albers GW, Amarenco P, et al. Addition of brain and carotid imaging to the $\operatorname{ABCD}(2)$ score to identify patients at early risk of stroke after transient ischaemic attack: a multicentre observational study. Lancet Neurol 2010;9:1060-9.

44. Coutts SB, Eliasziw M, Hill MD, et al. Hyperacute MR imaging and clinical predictor risk score predict dependent outcome after minor stroke and TIA. Stroke 2007;38:492.

45. Albers GW, Caplan LR, Easton JD, et al. Transient ischemic attack - proposal for a new definition. N Engl J Med 2002;347:1713-6.

46. Amsterdam EA, Wenger NK, Brindis RG, et al. 2014 AHA/ ACC guideline for the management of patients with non-STelevation acute coronary syndromes: a report of the American College of Cardiology/American Heart Association Task Force on Practice Guidelines. Circulation 2014;130:e344-426.

47. Wu CM, McLaughlin K, Lorenzetti DL, et al. Early risk of stroke after transient ischemic attack: a systematic review and meta-analysis. Arch Intern Med 2007;167:2417-22.

48. Wu CM, Manns BJ, Hill MD, et al. Rapid evaluation after high-risk TIA is associated with lower stroke risk. Can J Neurol Sci 2009;36:450-5.

49. Lavallée PC, Meseguer E, Abboud H, et al. A transient ischaemic attack clinic with round-the-clock access (SOSTIA): feasibility and effects. Lancet Neurol 2007;6:953-60.

50. Rothwell PM, Giles MF, Chandratheva A, et al. Effect of urgent treatment of transient ischaemic attack and minor stroke on early recurrent stroke (EXPRESS study): a prospective populationbased sequential comparison. Lancet 2007;370:1432-42.
51. Kennedy J, Hill MD, Ryckborst KJ, et al. Fast assessment of stroke and transient ischaemic attack to prevent early recurrence (FASTER): a randomised controlled pilot trial. Lancet Neurol 2007;6:961-9.

52. Wang Y, Wang Y, Zhao X, et al. Clopidogrel with aspirin in acute minor stroke or transient ischemic attack. $N$ Engl J Med 2013;369:11-9

53. Barnett HJ, Taylor DW, Eliasziw M, et al. Benefit of carotid endarterectomy in patients with symptomatic moderate or severe stenosis. North American Symptomatic Carotid Endarterectomy Trial Collaborators. N Engl J Med 1998;339:1415-25.

54. Hart RG, Halperin JL, Pearce LA, et al. Lessons from the Stroke Prevention in Atrial Fibrillation trials. Ann Intern Med 2003;138:831-8.

55. Hill MD. Stroke units in Canada. CMAJ 2002;167:649-50.

56. Indredavik B, Bakke F, Solberg R, et al. Benefit of a stroke unit: a randomized controlled trial. Stroke 1991;22:1026-31.

57. Collaborative systematic review of the randomised trials of organised inpatient (stroke unit) care after stroke. Stroke Unit Trialists' Collaboration. BMJ 1997;314:1151-9.

58. Zhu HF, Newcommon NN, Cooper ME, et al. Impact of a stroke unit on length of hospital stay and in-hospital case fatality. Stroke 2009;40:18-23.

59. Jørgensen HS, Nakayama H, Raaschou HO, et al. The effect of a stroke unit: reductions in mortality, discharge rate to nursing home, length of hospital stay, and cost. A community-based study. Stroke 1995;26:1178-82.

60. Candelise L, Gattinoni M, Bersano A, et al. Stroke-unit care for acute stroke patients: an observational follow-up study. Lancet 2007;369:299-305.

61. Seenan P, Long M, Langhorne P. Stroke units in their natural habitat: systematic review of observational studies. Stroke 2007;38:1886-92.

Competing interests: For work outside the scope of this review, Michael Hill reports consulting fees from Merck, nonfinancial support from Hoffmann-La Roche Canada Ltd. and grants from Covidien (Medtronic). He has a US patent pending (no. 62/086,077) for "systems and methods for assisting in decision-making and triaging for acute stroke patients," owns stock in Calgary Scientific Inc. (a medical imaging software company) and has received grant support from Alberta Innovates - Health Solutions, the Canadian Institutes of Health Research, the Heart and Stroke Foundation of Canada and the National Institute of Neurological Disorders and Stroke (US). No other competing interests were declared.

Affiliations: Department of Clinical Neurosciences, Cumming School of Medicine (Musuka), Department of Cardiac Sciences, Libin Cardiovascular Institute (Wilton, Traboulsi), Department of Clinical Neurosciences, Hotchkiss Brain Institute (Hill), and Departments of Radiology and Community Health Sciences, Cumming School of Medicine (Hill), University of Calgary, Calgary, Alta.

Contributors: Tapuwa Musuka wrote the first draft of the manuscript and coordinated editing and revision. Stephen Wilton, Mouhieddin Traboulsi and Michael Hill edited, revised and approved the final version of the manuscript. All authors agree to act as guarantors for the work.

Funding: Michael Hill is funded by the Heart and Stroke Foundation of Alberta, NWT \& Nunavut and by Alberta Innovates - Health Solutions. 